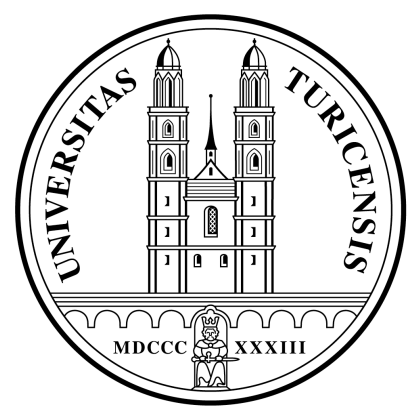

Institute for Empirical Research in Economics

University of Zurich

Working Paper Series

ISSN 1424-0459

Working Paper No. 128

An Application of Evolutionary Finance to Firms

Listed in the Swiss Market Index

Thorsten Hens, Klaus Reiner Schenk-Hoppé and Martin Stalder

August 2002 


\title{
An Application of Evolutionary Finance to Firms Listed in the Swiss Market Index *
}

\author{
Thorsten Hens \\ Klaus Reiner Schenk-Hoppé \\ Martin Stalder \\ Institute for Empirical Research in Economics \\ University of Zurich
}

August 21, 2002

\begin{abstract}
This paper presents an application of evolutionary portfolio theory to stocks listed in the Swiss Market Index (SMI). We study numerically the long-run outcome of the competition of rebalancing rules for market shares in a stock market with actual dividends taken from firms listed in the SMI. Returns are endogenous because prices are determined by supply and demand stemming from the rebalancing rules. Our simulations show that in competition with rebalancing rules derived from Mean-Variance Optimization, Maximum Growth Theory and Behavioral Finance, the evolutionary portfolio rule discovered in Hens and Schenk-Hoppé (2001) will eventually hold total market wealth. According to this simple rule the portfolio weights should be proportional to the expected relative dividends of the assets.
\end{abstract}

JEL-Classification: D52, D81, D83, G11.

Keywords: Evolutionary Finance, Behavioral Finance, CAPM, Rebalancing Rules, Growth Optimal Portfolio.

\footnotetext{
*Financial support by the national centre of competence in research "Financial Valuation and Risk Management" is gratefully acknowledged. The national centers in research are managed by the Swiss National Science Foundation on behalf of the federal authorities. Contact address: Institute for Empirical Research in Economics, University of Zurich, Blümlisalpstrasse 10, 8006 Zürich, Switzerland. Email: thens@iew.unizh.ch, klaus@iew.unizh.ch, martin.stalder@gmx.net
} 


\section{Introduction}

Recent empirical and experimental work has done a lot to undermine the long sustained belief in market rationality (see for example Campbell (2000), Hirshleifer (2001) and De Bondt (1999) for surveys). These important facts have initiated a new behavioral paradigm for finance that according to many researchers in the field might replace or at least complement traditional finance. It is currently believed that thinking in terms like excess volatility, irrational exuberance, market risk and loss aversion will soon substitute the cornerstones of traditional finance, mean-variance-analysis, arbitrage pricing and the efficient market hypothesis. While the fight of the rational and the behavioral finance paradigm is in its decisive stage, we argue that a third paradigm, evolutionary finance, should not be omitted. Thinking in terms of strategies, market selection and mutation seems to be very appropriate in finance. On the stock market, for example, a heterogeneous population of portfolio strategies interact frequently with each other - competing for market capital. Market selection is perhaps most severe on these markets and mutations respectively innovations occur frequently. A long time ago Friedman (1953) and Fama (1965) have recognized the power of evolutionary ideas in finance. Using these ideas they argued that the market naturally selects for the rational strategies. As an effect market selection would lead to market efficiency. This specific outcome of the market selection process could not be sustained in general. For example Shleifer (2000, Chap. 2.2) shows that under specific circumstances noise traders can earn a higher average rate of return than rational arbitrageurs. However, it may be asked whether Shleifer's example depends on a too narrowly defined set of strategies. The answer to this important question is the core of evolutionary finance. It can only be given in a precise but general model of the market selection process. Some considerable progress in the field of evolutionary finance has been made since Friedman (1953) and Fama (1965). This progress was made possible due to a formalization of evolutionary reasoning based on game theoretic concepts using computer simulations and advanced mathematical techniques. Many time series properties of asset prices, for example, have found an explanation by evolutionary reasoning (Arthur, Holland, LeBaron, Palmer, and Taylor (1997), LeBaron, Arthur, and Palmer (1999), Brock and Hommes (1997), and Lux (1994) among others). These results have also received very good recognition in practitioner's news letters (Mauboussin (1999)). In the area of portfolio theory, the seminal work of Blume and Easley (1992) has laid the foundations for a series of papers (Sandroni (2000), Blume and Easley (2001), Sciubba (1999), Hens and Schenk-Hoppé (2001), Evstigneev, Hens, and Schenk-Hoppé (2002b), Amir, Evstigneev, Hens, and 
Schenk-Hoppé (2001)) developing an evolutionary portfolio theory. This theory gives a general model of the market selection process in which the hypotheses put forward by Friedman and Fama can be studied for any set of assets and any set of strategies. It turns out that as long as there are excess returns there still exist strategies that can gain market wealth at the expense of the existing strategies. Moreover there is one strategy, the evolutionary portfolio rule discovered in Hens and Schenk-Hoppé (2001), that eliminates all excess returns and that will eventually hold total market wealth in the market selection process.

While the theoretical papers on evolutionary portfolio selection derive asymptotic results in idealized markets, the point of this paper is to apply the evolutionary ideas to stocks from the SMI. The portfolio choice considered in our paper is the decision how to allocate wealth among shares yielding a dividend as observed in the Swiss Market data. We focus attention on dynamic portfolio strategies. That is to say we view a modern capital market, like the SWX, as a heterogenous population of dynamic portfolio strategies. These strategies interact repeatedly via the market mechanism and are thereby competing for market capital. However instead of considering all theoretically possible dynamic portfolio rules we take a more pragmatic point of view here and restrict attention to simple rebalancing rules. A simple rebalancing rule holds certain portfolio weights constant for a long period. Hence if market prices fluctuate a rebalancing rule has to adjust the number of shares it holds so as to keep the proportions of wealth in its portfolio constant. Many institutional investors follow simple rebalancing rules. Some of them because they have committed to manage third parties money according to a certain asset allocation $^{1}$, some because they believe that rebalancing is an optimal behavior in volatile markets ${ }^{2}$ and some because they use trading strategies derived from some clever reasoning like contrarian behavior that in essence are rebalancing rules ${ }^{3}$. As Evstigneev, Hens, and Schenk-Hoppé (2002b) have demonstrated in the case of short-lived assets, the simple evolutionary rebalancing rule considered in this paper is not only able to outperform any other simple portfolio strategy but it will also dominate any general portfolio strategy given it is adapted to the price process. Hence it may be argued

\footnotetext{
${ }^{1}$ In many prospects of mutual funds some asset allocation, e.g. $60 \%$ technology stock and $40 \%$ brick and water stocks, is proposed as an optimal investment rule so that the investors would feel cheated if these proportions fall out of balance.

${ }^{2}$ Suppose for example that prices follow a random walk, an often hold assertion, then rebalancing means that on average one buys cheap and sells high!

${ }^{3}$ Following a contrarian behavioral strategy, like that of De Bondt and Thaler (1985) for example, one sells those stocks that have gone up and buys those that went down, which is also the main feature of rebalancing rules.
} 
that the restriction to simple rebalancing rules does not restrict the outcome of the market selection process.

Since from the market selection point of view the market interaction of the various portfolio rules is decisive, we cannot simply do an empirical study of the relative performance of rebalancing rules on a given return path. This would ignore the impact one strategy has on its competitors ${ }^{4}$. Hence we have to rely on simulations in order to show the would-be performance of various portfolio rules that are interacting in a market with the Swiss Market dividends. It turns out that the best rebalancing strategy for exogenous returns, the growth optimal portfolio, also called the maximum growth strategy (Hakansson 1970), is not necessarily the best performing strategy once market interaction is taken into account. Our simulations show that in competition with rebalancing rules derived from Mean-Variance Optimization, Maximum Growth Theory as well as Behavioral Finance, the Evolutionary Finance rule discovered in Hens and Schenk-Hoppé (2001) will eventually hold total market wealth. According to this simple rule the portfolio weights should be proportional to the expected relative dividends of the assets. Note that the portfolio weights used by the evolutionary strategy are based solely on fundamentals, ignoring any price fluctuations! As it turns out, in the long run as its wealth share grows, prices will stop fluctuating and settle down on the relative expected dividends of the assets because eventually only the single surviving evolutionary rule will determine market prices. This is of course a very strong prediction. Our simulations show that even though the final proceeds of the evolutionary process are huge (one gets total market wealth), one might have to wait really long before this happens. However even a very modest investor will be pleased with the growth of the market share of the evolutionary rule. Starting from equal grounds, after 4 periods the evolutionary rule has doubled its market share for the first time and it takes another 46 periods to double it once more. And starting from a market share of only $0.1 \%$ which is $1 \%$ of the others market shares, the first doubling of the evolutionary rule's market shares happens after only 2 periods, the second doubling after 9 periods and the third doubling after 40 periods and after 79 periods it has reached 10 times the market share it started from. Hence in contrast to the well know critique on the maximum growth literature, put forward for example by Rubinstein (1991), the convergence of the process is much faster when prices are exogenous. It should also be noted

\footnotetext{
${ }^{4}$ Note that we are not claiming that individual traders have a huge impact on market prices. From an evolutionary point of view the strategy according to which market capital is managed is crucial, it is not important whether fund $\mathrm{X}$ or fund $\mathrm{Y}$ or both are using this strategy. Hence it may be that a certain commonly used strategy like the mean-variancerule has a huge impact while no individual fund has any impact on market prices.
} 
that every run of the simulation looks pretty much the same. Indeed, the variance over the different runs of the simulations is negligible. Based on 30 runs we found that the standard deviation of the market shares averaged over all periods is only $0.21 \%$.

In passing we would like to mention that for the case of long-lived assets considered here, so far the theoretical literature has not been able to prove what our simulations show: the global convergence of the evolutionary process towards a situation in which all wealth is managed by the evolutionary rule found in Hens and Schenk-Hoppé $(2001)^{5}$. Hence our "application" of the evolutionary portfolio theory also hints at new theoretical results.

In the next section 2 we briefly recall the evolutionary portfolio model of this paper. Section 3 gives some intuition on evolutionary investment. Section 4 presents the application of this model to a market with dividends taken from the SMI. Section 5 presents the results and section 6 provides the intuition thereof. Section 7 concludes. Data and portfolio rules are collected in an appendix. The Excel scripts used in the simulations are available on the web at www.iew.unizh.ch/grp/hens.

\section{An Evolutionary Stock Market Model}

We consider a financial market with $K$ long-lived assets and cash. Time is discrete and denoted by $t=\ldots,-1,0,1, \ldots$. Each asset $k=1, \ldots, K$ pays off a dividend per share at the beginning of every period and before trade takes place in this period. $D_{t}^{k} \geq 0$ denotes the total dividend paid to all shareholders of asset $k$ at the beginning of period $t$. $D_{t}^{k}$ depends on the history of states of the world $\omega^{t}=\left(\ldots, \omega_{t-1}, \omega_{t}\right)$ where $\omega_{t} \in \Omega$ is the state revealed at the beginning of period $t$. $\Omega$ is assumed to be finite, and every state is drawn with some strictly positive probability.

Dividend payoffs are in terms of cash. Cash is used to buy consumption goods. It is not used to store value. The supply of every asset $k, s_{t}^{k}$, is exogenous and normalized to 1 . The supply of cash $s_{t}^{0}$ is given by the total dividends of all assets.

There are finitely many portfolio rules (also referred to as investment strategy) indexed by $i=1, \ldots, I, I \geq 2$, each is pursued by an investor. The portfolio rule of investor $i$ is a fixed constant proportions strategy $\lambda^{i}=$ $\left(\lambda_{k}^{i}\right)_{k=0, \ldots, K}$ with $\lambda_{k}^{i} \in[0,1]$ for all $k=0, \ldots, K$ and $\sum_{k=0}^{K} \lambda_{k}^{i}=1$. For each

\footnotetext{
${ }^{5}$ For the case of short-lived assets, global convergence to the evolutionary rule has been demonstrated under very general conditions by Amir, Evstigneev, Hens, and SchenkHoppé (2001). For long-lived assets, Evstigneev, Hens, and Schenk-Hoppé (2002a) are able to demonstrate that this rule is the unique evolutionary stable strategy.
} 
$k \geq 1, \lambda_{k}^{i}$ is the fraction of the wealth investor $i$ assigns to the purchase of the risky asset $k . \lambda_{0}^{i}$ is the fraction of wealth hold in cash. Investment strategies are distinct across investors ${ }^{6}$. To ensure that all asset prices are strictly positive, we assume that at least one strategy is completely mixed, i.e. $\lambda_{k}^{i} \in(0,1)$ for all $k$.

For a given portfolio rule $\lambda^{i}$ and wealth $w_{t}^{i}$, the portfolio purchased by investor $i$ at the beginning of period $t$ is given by

$$
\theta_{t, k}^{i}=\frac{\lambda_{k}^{i} w_{t}^{i}}{p_{t}^{k}} \quad k=0,1, \ldots, K .
$$

$\theta_{t, 0}^{i}$ is the units of cash and $\theta_{t, k}^{i}$ is the units of assets hold by investor $i$. Since we have normalized the supply of the long-lived assets to $1, \theta_{t, k}^{i}$ is the percentage of all shares issued of asset $k$ that investor $i$ purchases. $p_{t}^{k}$ denotes the market clearing price of asset $k$ in period $t$. We normalize the price for cash $p_{t}^{0}=1$ in every period $t$. The price of the consumption good is also the numeraire.

For any portfolio holdings of agents $\left(\theta_{t}^{i}\right)_{i=1, \ldots, I}$ the market equilibrium conditions for cash and long-lived assets are given by

$$
\sum_{i=1}^{I} \theta_{t, k}^{i}=s_{t}^{k}, \quad k=0, \ldots, K,
$$

where the supply of the risky assets is $s_{t}^{k}=1$, while the supply of cash is given by

$$
s_{t}^{0}=\sum_{k=1}^{K} D_{t}^{k}\left(\omega^{t}\right)
$$

The budget constraint of investor $i$ in every period $t=0,1, \ldots$

$$
\sum_{k=0}^{K} p_{t}^{k} \theta_{t, k}^{i}=w_{t}^{i}
$$

is fulfilled since the fractions $\lambda_{k}^{i}, k=0, \ldots, K$, add up to one, see (1).

Since every investor consumes the fraction $\lambda_{0}^{i}$ of his wealth in any period, the wealth of investor $i$ (in terms of the price of the consumption good) at the beginning of period $t+1$ and after dividends are payed turns out to be given by

$$
w_{t+1}^{i}=\sum_{k=1}^{K}\left(D_{t+1}^{k}\left(\omega^{t+1}\right)+p_{t+1}^{k}\right) \theta_{t, k}^{i}
$$

\footnotetext{
${ }^{6}$ The case of investors pursuing the same portfolio rule can be handled as follows. Investors with the same strategy set up a fund with claims equal to their initial share.
} 
The wealth changes because of dividend payments and capital gains. The cash $\theta_{0}^{i}(t)$ hold by every investor is consumed. The amount of cash available in any one period stems only from dividend payments.

The market-clearing price $p_{t}^{k}$ for the risky assets $(k \geq 1)$ can be derived from (2) by inserting (1). One finds

$$
p_{t}^{k}=\sum_{i=1}^{I} \lambda_{k}^{i} w_{t}^{i}=\lambda_{k} w_{t}
$$

where $\lambda_{k}=\left(\lambda_{k}^{1}, \ldots, \lambda_{k}^{I}\right)$ and $w_{t}^{T}=\left(w_{t}^{1}, \ldots, w_{t}^{I}\right)$.

Inserting (1) and (6) in (5) one obtains

$$
w_{t+1}^{i}=\sum_{k=1}^{K}\left(D_{t+1}^{k}\left(\omega^{t+1}\right)+\lambda_{k} w_{t+1}\right) \frac{\lambda_{k}^{i} w_{t}^{i}}{\lambda_{k} w_{t}}
$$

This is an implicit equation for the wealth of each investor $i, w_{t+1}^{i}$, for a given distribution of wealth $w_{t}$ across investors. It is convenient for the further analysis to define

$$
A_{t}^{i}=\sum_{k=1}^{K} D_{t+1}^{k}\left(\omega^{t+1}\right) \frac{\lambda_{k}^{i} w_{t}^{i}}{\lambda_{k} w_{t}}, \quad \text { and } \quad B_{t}^{i, k}=\frac{\lambda_{k}^{i} w_{t}^{i}}{\lambda_{k} w_{t}}
$$

The time index refers to the dependence on wealth: $A_{t}^{i}$ and $B_{t}^{i, k}$ both depend on the wealth in period $t$. (7) can now be written as

$$
w_{t+1}^{i}=A_{t}^{i}+\sum_{k=1}^{K} B_{t}^{i, k} \lambda_{k} w_{t+1}
$$

and thus

$$
w_{t+1}=A_{t}+B_{t} \Lambda w_{t+1}
$$

where $\Lambda^{T}=\left(\lambda_{1}^{T}, \ldots, \lambda_{K}^{T}\right) \in \mathbb{R}^{I \times K}$ is the matrix of portfolio rules, and $B_{t} \in$ $\mathbb{R}^{I \times K}$ is the matrix of portfolios in period $t . A_{t}^{T}=\left(A_{t}^{1}, \ldots, A_{t}^{I}\right) \in \mathbb{R}^{I}$ are the dividends payments, and $B_{t} \Lambda w_{t+1}$ are the capital gains.

We need to solve (9) to derive an explicit law of motion - a random dynamical system - governing the distribution of wealth across strategies. One has

$$
w_{t+1}=\left[\operatorname{Id}-B_{t} \Lambda\right]^{-1} A_{t}
$$

with Id being the identity matrix in $\mathbb{R}^{I \times I}$. The matrix $\left[\operatorname{Id}-B_{t} \Lambda\right]$ is invertible and its inverse is positive because the positive matrix $\left[B_{t} \Lambda\right]$ can be considered 
as an input-output matrix for which the vector $w_{t}=\left(w_{t}^{1}, \ldots, w_{t}^{I}\right)$ shows that it is productive: Post multiplying $\left[\mathrm{Id}-B_{t} \Lambda\right]$ by $w_{t}^{T}$ yields the vector $\lambda_{0}\left(w_{t}^{1}, \ldots, w_{t}^{I}\right)^{T}>>0$. Hence by the proof of proposition 5.A.A.1 in MasColell, Whinston, and Green (1995) the matrix $\left[\mathrm{Id}-B_{t} \Lambda\right]$ is invertible and its inverse is positive.

For every distribution of wealth $w_{t}$ and every state of nature $\omega_{t},(11)$ yields the distribution of wealth $w_{t+1}$ in the subsequent period in time. We can state the law of motion in the convenient form

$$
w_{t+1}=f_{t}\left(\omega^{t+1}, w_{t}\right)
$$

where

$$
f_{t}\left(\omega^{t+1}, w_{t}\right)=\left[\operatorname{Id}-\left[\frac{\lambda_{k}^{i} w_{t}^{i}}{\lambda_{k} w_{t}}\right]_{i}^{k} \Lambda\right]^{-1}\left[\sum_{k=1}^{K} D_{t+1}^{k}\left(\omega^{t+1}\right) \frac{\lambda_{k}^{i} w_{t}^{i}}{\lambda_{k} w_{t}}\right]_{i}
$$

The final step is to derive the law of motion for the investors' market shares. This will complete the derivation of the evolutionary stock market model.

It is clear that other things being equal, a smaller rate of consumption leads to a higher growth rate of wealth. To avoid this tradeoff between superiority of a portfolio rule and higher rate of consumption, the following assumption is made.

(A) All investors have the same rate of consumption, i.e. $\lambda_{0}^{i}=\lambda_{0}$ for all $i=1, \ldots, I$.

Without assumption (A) the evolution of wealth would be biased in favor of investors with a high saving rate.

Aggregating (7) over investors, one finds

$$
W_{t+1}=\sum_{k=1}^{K} D_{t+1}^{k}\left(\omega^{t+1}\right)+\sum_{k=1}^{K} \lambda_{k} w_{t+1}=D_{t+1}\left(\omega^{t+1}\right)+\left(1-\lambda_{0}\right) W_{t+1}
$$

where $D_{t+1}\left(\omega^{t+1}\right)=\sum_{k=1}^{K} D_{t+1}^{k}\left(\omega^{t+1}\right)$ is the aggregate dividend payment. The last equality holds because $\sum_{k=1}^{K} \lambda_{k} w_{t+1}=\sum_{i=1}^{I} \sum_{k=1}^{K} \lambda_{k}^{i} w_{t+1}^{i}=(1-$ $\left.\lambda_{0}\right) \sum_{i=1}^{I} w_{t+1}^{i}$.

Equation (13) implies

$$
W_{t+1}=\frac{D_{t+1}\left(\omega^{t+1}\right)}{\lambda_{0}}
$$

The economy grows (or declines) with rate $D_{t+1}\left(\omega^{t+1}\right) /\left(\lambda_{0} W_{t}\right)$. The growth rate is thus the ratio of the rate at which additional wealth is injected 
by dividends, $D_{t+1}\left(\omega^{t+1}\right) / W_{t}$, to the rate at which wealth is withdrawn from the process for consumption, $\lambda_{0}$.

The market share of investor $i$ is $r_{t}^{i}=w_{t}^{i} / W_{t}$. Using (14) and exploiting the particular structure of the variables (8) that define the law of motion (12), we obtain

$$
r_{t+1}=\frac{\lambda_{0}}{D_{t+1}\left(\omega^{t+1}\right)} f_{t}\left(\omega^{t+1}, r_{t}\right)
$$

or, equivalently,

$$
r_{t+1}=\lambda_{0}\left(\operatorname{Id}-\left[\frac{\lambda_{k}^{i} r_{t}^{i}}{\lambda_{k} r_{t}}\right]_{i}^{k} \Lambda\right)^{-1}\left[\sum_{k=1}^{K} d_{t+1}^{k}\left(\omega^{t+1}\right) \frac{\lambda_{k}^{i} r_{t}^{i}}{\lambda_{k} r_{t}}\right]_{i}
$$

where $d_{t+1}^{k}\left(\omega^{t+1}\right)=D_{t+1}^{k}\left(\omega^{t+1}\right) / D_{t+1}\left(\omega^{t+1}\right)$ is the relative dividend payment of asset $k$. (16) is called the market selection process.

Eq. (16) generates a (non-autonomous) random dynamical system on the simplex $\Delta^{I}=\left\{r \in \mathbb{R}^{I} \mid r^{i} \geq 0, \sum_{i} r^{i}=1\right\}$. For any initial distribution of wealth $w_{0} \in \mathbb{R}_{+}^{I}$, (16) defines the path of market shares on the event tree with branches $\omega^{t}$. The initial distribution of market shares is given by $\left(r_{0}^{i}\right)_{i}=\left(w_{0}^{i} / W_{0}\right)_{i}$.

The wealth of an investor $i$ in any period in time can be derived from her market share and the aggregate wealth, defined by (14), as

$$
w_{t+1}^{i}=\frac{D_{t+1}\left(\omega^{t+1}\right)}{\lambda_{0}} r_{t+1}^{i}
$$

The further analysis is restricted to the stationary case. We make the following assumption.

(B) Stationary (i.i.d.) relative dividend payments $d_{t}^{k}\left(\omega^{t}\right)=d^{k}\left(\omega_{t}\right)$, for all $k=1, \ldots, K$.

\section{$3 \quad$ Evolutionary Investment}

In this section we derive and motivate an evolutionary investment rule $\lambda^{*}$ which was first discovered in Hens and Schenk-Hoppé (2001) in a simpler model. This portfolio rule is the only candidate for a rule that can attract all market wealth. That is to say, supposing the market selection process (16) converges, then the portfolio rule that conquers the whole market has to be the evolutionary investment rule $\lambda^{*}$. It is important to point out that in all our simulations convergence of the process was obtained. We also give an interpretation of the evolutionary investment rule $\lambda^{*}$ in terms of the wellknown growth optimal portfolio rule (Hakansson 1970). It turns out that $\lambda^{*}$ 
is the growth optimal portfolio rule in a population of rules which generates prices equal to $\lambda^{*}$.

To this end we analyze the market selection process close to the one-ownsall states, i.e. we investigate the local dynamics close to the vertices of the simplex of market shares. We make the non-redundancy assumption

(C) Absence of redundant assets, i.e. the matrix of relative dividend payments $\left(d^{k}(\omega)\right)_{\omega \in \Omega, \ldots}^{k=1, K}$ has full rank.

Under this assumption these states are the only deterministic steady states in pools of simple strategies (Evstigneev, Hens, and Schenk-Hoppé 2002a).

Suppose one investor, say investor $j$, owns the market wealth. The investment strategy, $\lambda^{j}$, of this investor determines prices in this case. One has $p_{t}^{k}=\lambda_{k}^{j} W_{t}$, and $p_{t+1}^{k}=\lambda_{k}^{j} W_{t+1}$. Under this assumption, (5) yields

$$
\begin{aligned}
r_{t+1}^{i} & =\sum_{k=1}^{K} \frac{D_{t+1}^{k}\left(\omega^{t+1}\right)+p_{t+1}^{k}}{W_{t+1}} \frac{\lambda_{k}^{i} w_{t}^{i}}{p_{t}^{k}}=\sum_{k=1}^{K}\left(\frac{D_{t+1}^{k}\left(\omega^{t+1}\right)}{W_{t+1}}+\lambda_{k}^{j}\right) \frac{\lambda_{k}^{i} w_{t}^{i}}{\lambda_{k}^{j} W_{t}} \\
& =\sum_{k=1}^{K}\left(\lambda_{0} d^{k}\left(\omega_{t+1}\right) \frac{\lambda_{k}^{i}}{\lambda_{k}^{j}}+\lambda_{k}^{i}\right) r_{t}^{i}=\left(1-\lambda_{0}+\lambda_{0} \sum_{k=1}^{K} d^{k}\left(\omega_{t+1}\right) \frac{\lambda_{k}^{i}}{\lambda_{k}^{j}}\right) r_{t}^{i}
\end{aligned}
$$

where $r_{t}^{i}=\frac{w_{t}^{i}}{W_{t}}, W_{t+1}=D_{t+1}\left(\omega^{t+1}\right) /\left(1-\lambda_{0}\right)$, and $\sum_{k=1}^{K} \lambda_{k}^{i}=1-\lambda_{0}$.

The exponential growth rate of investor $i$ 's market share at $\lambda^{j}$-prices can be inferred from this equation. It is given by,

$$
g_{\lambda^{j}}\left(\lambda^{i}\right)=\mathbb{E} \ln \left[1-\lambda_{0}+\lambda_{0} \sum_{k=1}^{K} d^{k}(\omega) \frac{\lambda_{k}^{i}}{\lambda_{k}^{j}}\right]
$$

One can show Evstigneev, Hens, and Schenk-Hoppé (2002a)

Theorem 1 The portfolio rule $\lambda^{*}$, defined by

$$
\lambda_{k}^{*}=\left(1-\lambda_{0}\right) \mathbb{E} d^{k}(\omega)
$$

is the only investment strategy that is locally stable in any pool of portfolio rules. That is, $g_{\lambda^{*}}(\lambda)<0$ and $g_{\lambda}\left(\lambda^{*}\right)>0$ for all $\lambda \neq \lambda^{*}$.

Hence supposing the evolutionary process of wealth converges, it can only converge to $\lambda^{*}$. Moreover, as the following corollary shows the strategy $\lambda^{*}$ is related to the growth optimal portfolio. 
Corollary 1 The portfolio rule $\lambda_{k}^{*}=\left(1-\lambda_{0}\right) \mathbb{E} d^{k}(\omega)$ is the growth optimal investment strategy in a population where itself determines the asset prices, i.e.

$$
\lambda^{*}=\arg \max _{\lambda: \sum_{k} \lambda_{k}=1-\lambda_{0}} \mathbb{E} \ln \left(\sum_{k} \frac{d^{k}(\omega)+\lambda_{k}^{*}}{\lambda_{k}^{*}} \lambda_{k}\right) .
$$

Corollary 1 follows from $g_{\lambda^{*}}(\lambda)<0$ together with the observation that $g_{\lambda^{*}}\left(\lambda^{*}\right)=0$.

Before we pass on to the application we like to mention that one implication of equation (18) is that underdiversification is fatal for investment. Supposing some strategy does not use all assets it can easily be driven out by any completely diversified strategy. In particular the illusionary diversification rule according to which one puts equal weights on all assets can drive out sophisticated rules based on some optimization criterion like for example the mean-variance rule.

Corollary 2 Suppose some incumbent rule $\lambda^{j}$ with $\lambda_{k}^{j}=0$ for some asset $k$ has conquered the market then any portfolio rule $\lambda^{i}$ with $\lambda_{k}^{i}>0$ for all $k$ grows against $\lambda^{j}$, i.e. $g_{\lambda^{j}}\left(\lambda^{i}\right)>0$.

\section{Application to the SMI}

In this section we apply the general evolutionary portfolio theory model outlined before to data from the Swiss Market Index. To this purpose we consider the total dividends paid by 13 stocks from the years 1989 to 2001, see appendix A for the data. Those 13 years and those 13 stocks have been selected because for other years and other stocks we could not get the necessary data. We interpret this data in terms of our model in the following way. First we assume that the 13 years are 13 realizations of a stationary dividend process. Hence each date $t=1, \ldots, 13$ is identified with a state $s=1, \ldots, 13$. Each row of the matrix in appendix A is assumed to model the total dividends $D^{k}\left(\omega_{z}\right)$, $\mathrm{k}=1, \ldots, 13$ where $z=1, \ldots 13$ denotes the 13 states of this stationary process. As recently the minimum par value for shares was lowered, some firms did not pay dividends but partially repaid par value for tax reasons. We considered these payments as dividends as long as they were in reasonable range of historically paid amounts.

All portfolio strategies that we consider have one property in common. They devote the same proportion of wealth to cash holdings which without loss of generality is assumed to be $10 \%$, i.e. we assume $\lambda^{0}=0.1$.

We consider two types of portfolio rules. Those based solely on the exogenous dividends and those based on the endogenous returns. Of the first 
type is the behavioral finance rule which Benartzi and Thaler (1998) have called illusionary diversification,

$$
\lambda_{k}^{i l l u}=\frac{1-\lambda_{0}}{K}
$$

for all $k=1, . ., K$. According to this rule budget shares are set equal for all risky assets. Benartzi and Thaler (1998) found that surprisingly many investors use this naive rule. Of the first type is also the evolutionary portfolio rule from Theorem 1 which was discovered in Hens and Schenk-Hoppé (2001):

$$
\lambda_{k}^{*}=\left(1-\lambda_{0}\right) \mathbb{E} d^{k}
$$

for all $k=1, . ., K$. The evolutionary rule presumes that agents can form expectations correctly. It is however well known from behavioral finance that actual decisions of investors are based on perceived probabilities that may not coincide with the probabilities that govern the relevant stochastic process. To allow for this behavioral distortion Tversky and Kahnemann (1992) have suggested a certain transformation function $\alpha:[0,1] \rightarrow[0,1]$ that overstates small probabilities and that understates high probabilities. This function is known as the cumulative prospect theory. We have used the cumulative prospect theory function as suggested by Tversky and Kahnemann (1992) to create a second behavioral finance rule based on the portfolio rule $\lambda^{*}$. That is to say the portfolio rule based on cumulative prospect theory is given by:

$$
\lambda_{k}^{c p t}=\alpha\left(\lambda_{k}^{*}\right)
$$

for all $k=1, . ., K$. The second type of portfolio rules that we consider are those based on returns. Since we only want to consider simple portfolio rules, i.e. those with time independent budget shares, we have to choose some prices that remain constant in the computation of the returns. In order not to base the second type of portfolio rules on some unreasonable prices we give them the advantage of allowing them to use the prices that eventually will emerge in the evolutionary process. Since we are mainly interested in the long run behavior of the process these are the prices that determine the long run returns. And as it turned out those prices are given by $\lambda^{*}$. As an alternative set of prices that will also give rise to portfolio rules based on dividends we have taken the case of identical prices for all assets.

One of the most prominent examples of return based portfolio rules is the mean-variance rule suggested by Markowitz (1952). This rule is certainly one of the cornerstones of traditional finance and does not require any further elaboration. Using both sets of prices this results in:

$$
\lambda^{\mu-\sigma}\left(\lambda^{*}\right) \text { and } \lambda^{\mu-\sigma}(\mathbf{1}) .
$$


The second type of portfolio rule based on returns is the growth optimal portfolio as suggested for example by Hakansson (1970). This portfolio strategy maximizes the expected growth rate of wealth on a given return process. In its most general form this portfolio strategy is allowed to adapt to the endogenous fluctuations of the returns. It then maximizes the expected logarithm of the returns, which is also known as the Kelly rule, Kelly (1956). In this most general from it is clearly unbeatable in the long run perspective taken in this paper. However in this general form it is quite difficult to actually compute this rule. One way of interpreting the results of this paper is to say that with endogenous returns there is a pretty easy short cut to determine a simple portfolio rule that eventually coincides with the Kelly rule: Use $\lambda^{*}$ and thus simply divide your income proportional to the expected relative dividends. This is because as we have argued above, $\lambda^{g o p}\left(\lambda^{*}\right)=\lambda^{*}$. It is however well known that the growth optimal rule is very sensitive to mis-specifications of the returns expectations it is based on. In this paper, as an example for such mis-specifications we consider the growth optimal portfolio based on the wrong belief that returns are determined only by the dividends, i.e. by fixing all prices to be equal to one.

$$
\lambda^{g o p}(\mathbf{1})
$$

Appendix B shows the portfolio rules that have been computed according to the various strategies outlined so far. One apparent observation is that the portfolio strategies based on endogenous returns are underdiversified. The mean-variance-strategy only uses 4 and the growth optimal portfolio only uses 1 out of the 13 assets! As we have argued above underdiversification is fatal for survival in the market selection process. Therefore we do the mean-variance rule yet another favor and make it completely diversified by devoting to any asset at least the smallest positive budget share occurring in the underdiversified portfolio. This ad hoc diversification rule is often used in praxis:

$$
\lambda_{\epsilon}^{\mu-\sigma}\left(\lambda^{*}\right)
$$

Thus all together we consider the market selection process given by equation (16) when it is run by these 8 portfolio rules.

\section{$5 \quad$ Results of the Market Selection Process}

Given the dividend matrix and the strategies described above we have done simulations of the market selection process with different initial wealth shares for $\lambda^{*}$, different number of periods. In our final simulation we have also included noise trading as an additional strategy. 


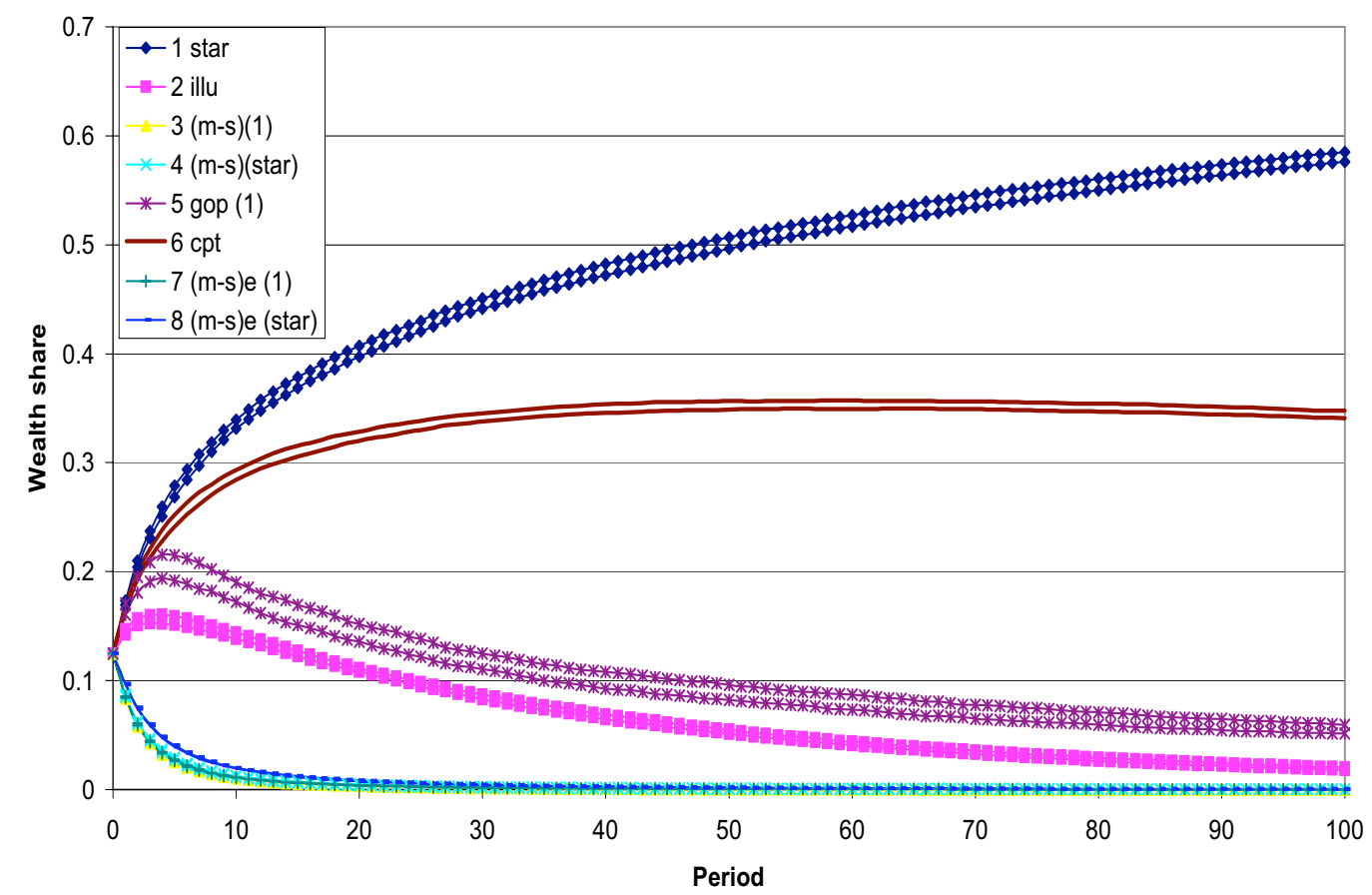

Figure 1: Evolution of the average market shares of the various strategies over time. (Average taken over 30 runs.) Confidence intervals.

Figure 1 is based on 30 runs of the market selection process with equal initial wealth of the 8 strategies described above. Each run was conducted for 100 periods. The charts in figure 1 are the average market shares of the various strategies, averaged over the 30 runs. Moreover we have indicated the confidence interval at a one standard deviation step by some upper and lower intervals displayed every 10 periods. The standard deviation turns out to be pretty small with a maximum value of $1 \%$ and an average value of only $0.21 \%$. We can see from figure 1 that the market share of $\lambda^{*}$ increases steadily from $10 \%$ to $60 \%$ while the other strategies' market shares have a clear downward trend although some of them initially increase.

Figure 2 shows the prices that are implied by the evolution of market shares. It is astonishing to see that prices converge quite rapidly to their rational values which are determined by $\lambda^{*}$.

Figure 3 is based on 30 runs of the market selection process with a market share of only $0.1 \%$ for $\lambda^{*}$ and equal initial wealth of $14.3 \%$ each for the 7 other strategies described above. Each run was conducted for 1000 periods. The charts in figure 3 give the average market shares of the various strategies, averaged over the 30 runs. Moreover we have indicated the confidence interval at a one standard deviation step by some upper and lower intervals. The 


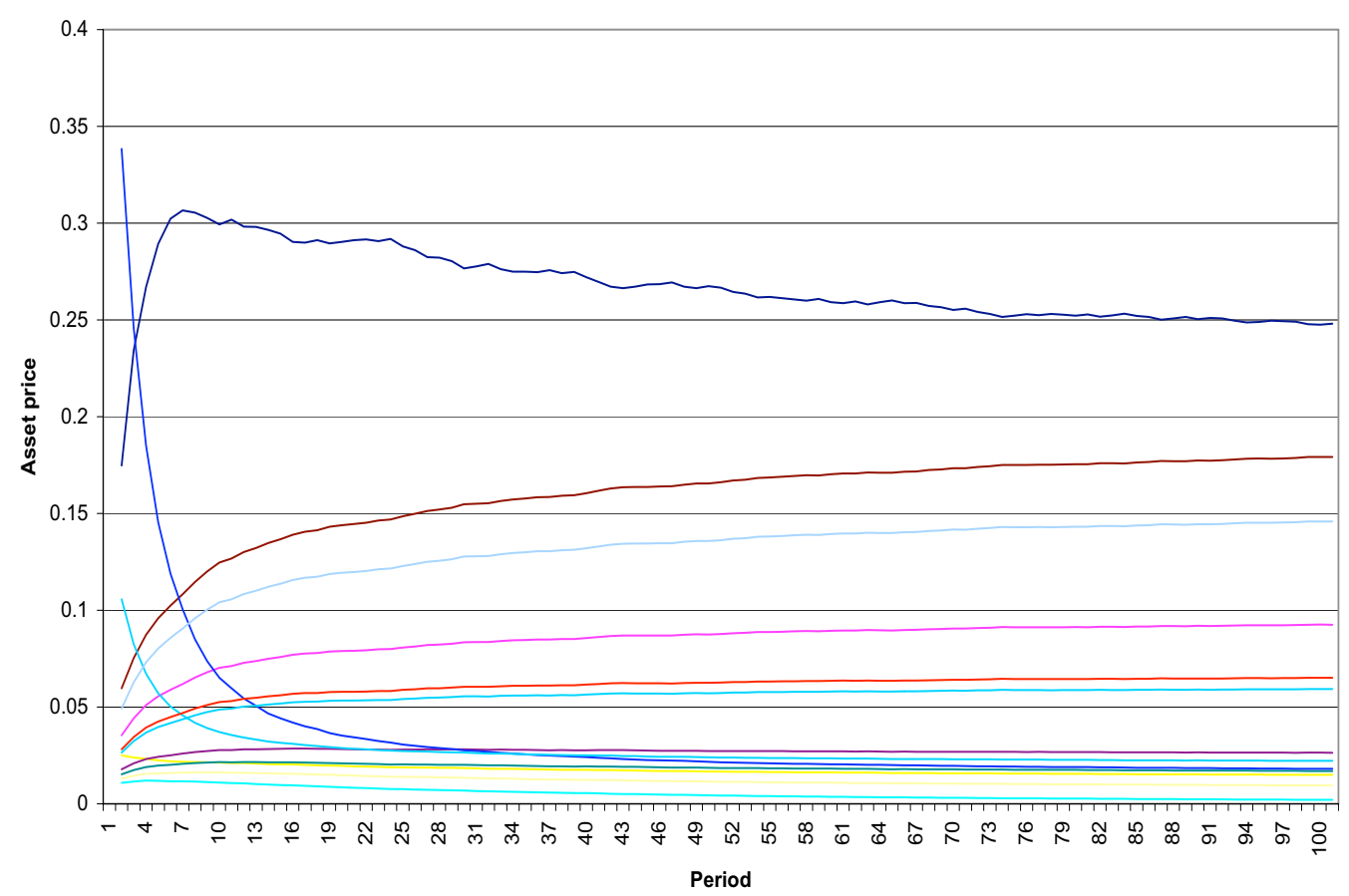

Figure 2: Evolution of share prices over time for one sample path of the dividend process.

confidence intervals are so narrow that they can hardly be visualized. Note that the standard deviation is again pretty small. Figure 3 displays an interesting population dynamics. As long as $\lambda^{*}$ is small, its behavioral finance variation $\lambda^{c p t}$ drives out any other strategy. However $\lambda^{*}$ grows steadily and eventually drives out and replaces $\lambda^{c p t}$. Note that the chart of $\lambda^{*}$ is s-shaped. While $\lambda^{*}$ is small it grows slowly, then it has a rapid take off and eventually when more and more competitors got close to extinction it slows down again. Even though $\lambda^{*}$ needs some time to conquer a considerable share of the market, starting from the $0.1 \%$ level it is able to double its share more rapidly than starting from the $10 \%$ level.

In figure 4 we have added noise traders to the picture. That is to say we included an eighth strategy that in every period chooses the budget shares randomly from some uniform distribution over the simplex. We endow the noise strategy with $55 \%$ of the total market wealth. This strategy is loosing rapidly. The performance of the other strategies is not much changed by noise trading. However, with noise, as figure 5 shows, the prices display excess volatility which mimics the observation of Shiller (1981) for the Dow Jones in the years 1928-1978.

All simulations can be verified from the excel sheets that we have made 


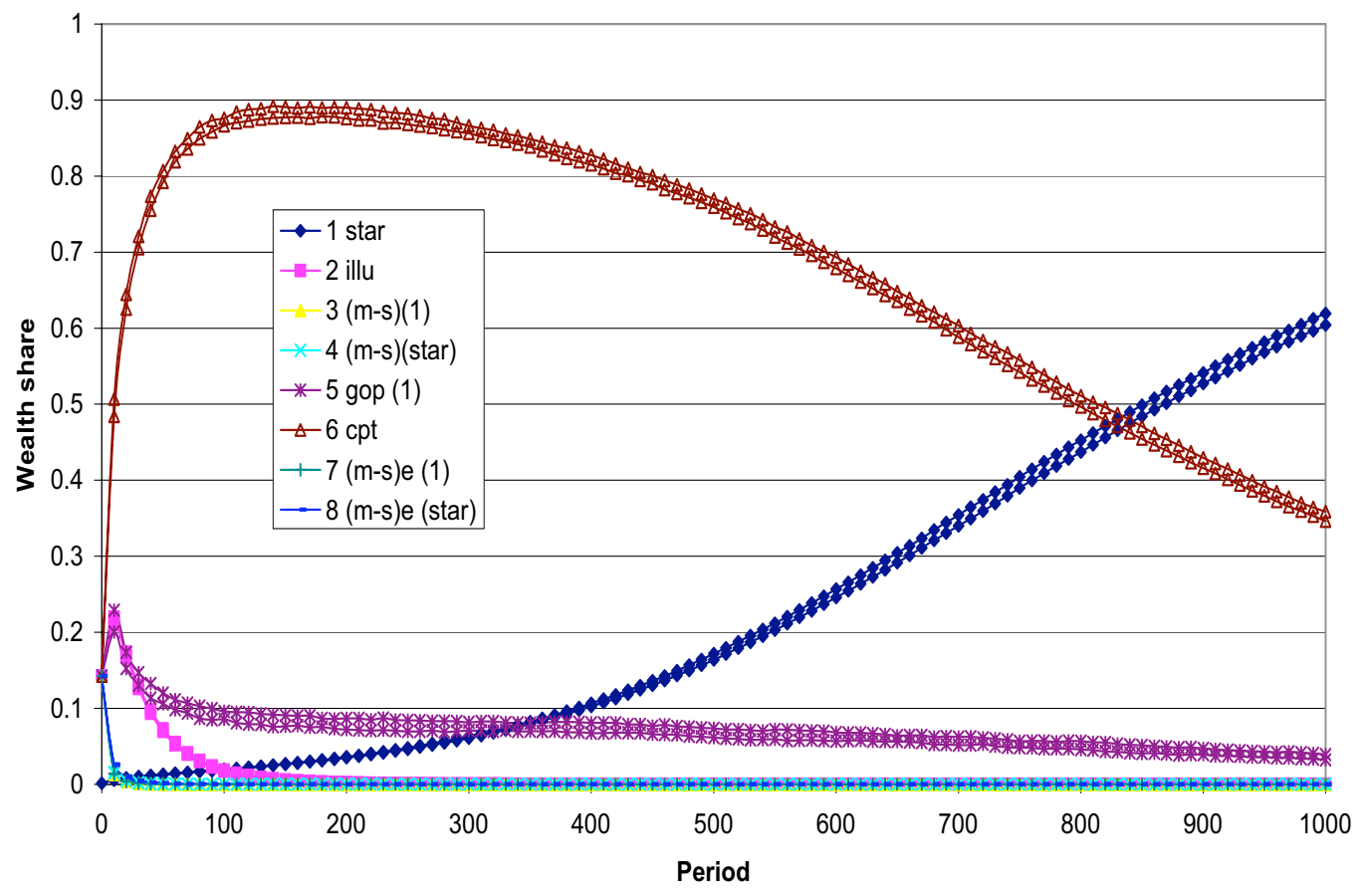

Figure 3: Evolution of the average market shares of the various strategies over time. (Average taken over 30 runs.) Initial market share of $\lambda^{*}$ is $0.1 \%$.

available on www.iew.unizh.ch/grp/hens.

\section{Some Intuition for the Results}

To get some intuition for the striking results obtained in the previous section it is instructive to recall the results of the theoretical literature. This literature considers an investment problem with stationary dividends in which the returns at any point in time are completely re-invested for the next period. The starting point was Breiman (1961)'s observation that the best strategy for repeatedly betting on the occurrence of a finite number of states is to divide the wealth placed on these bets proportional to the probabilities of occurrence of the states. This rule has thus been called betting your beliefs. That is to say, if one holds fixed these proportions then by the Law of Large Numbers one will maximize the expected growth rate of your wealth. Note that taking the long run perspective of the Law of Large Numbers risk does not matter because any short run under performance that still leaves some positive wealth can eventually be recovered in the long run. This idealistic point of view on the risk involved in portfolio formation is common to all 


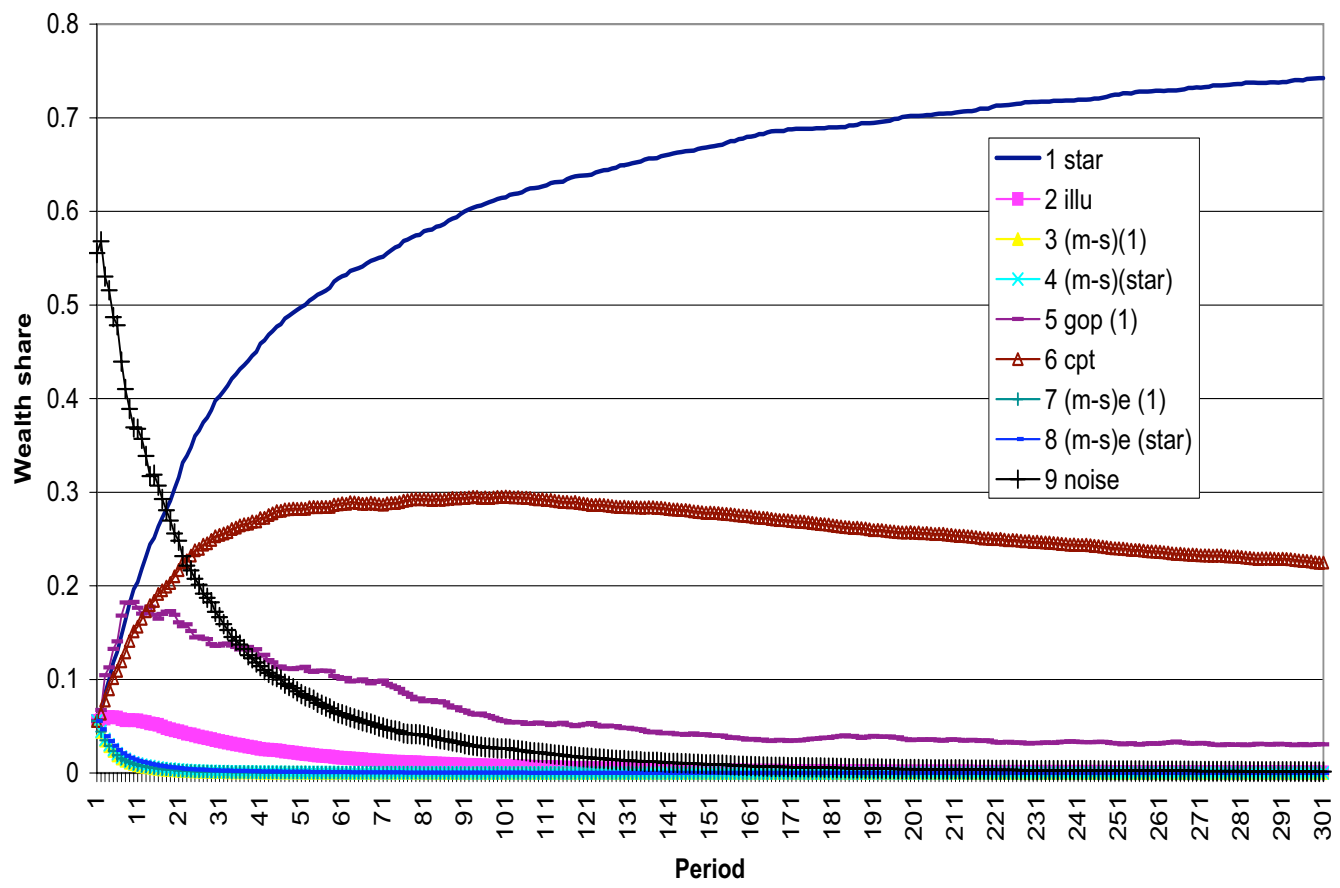

Figure 4: Evolution of the market shares in the model with noise traders initially owning $55 \%$ of the total market wealth. (One sample path of the dividend process.)

papers on evolutionary portfolio theory. The next step in this literature was to consider a market for the bets on the various states. Thus if demand for any one bet were high then the price for this bet will be high and one might argue that one should rather go for the other bets that offer a more attractive return. However, as Blume and Easley (1992) have shown this is not true. The best portfolio rule is still to bet your beliefs. In Breiman (1961) as well as in Blume and Easley (1992) bets can be identified with states because, they were considering a complete set of Arrow-securities. Evstigneev, Hens, and Schenk-Hoppé (2002b) have generalized the set up of Blume and Easley (1992) to allow for any complete or incomplete asset structure. As these authors show, the correct generalization of betting your beliefs is then to divide income proportionally to the expected payoffs of the securities. A major short coming of the literature so far was the assumption of short lived assets. According to this assumption in every period, after having paid off, the asset is liquidated and an identical asset is reborn. Wealth is assumed to be perishable so that it can only be transferred to later periods by investing once more in the exogenously supplied assets. Sandroni (2000) and Blume and Easley (2001) are the first models of this literature with long lived as- 


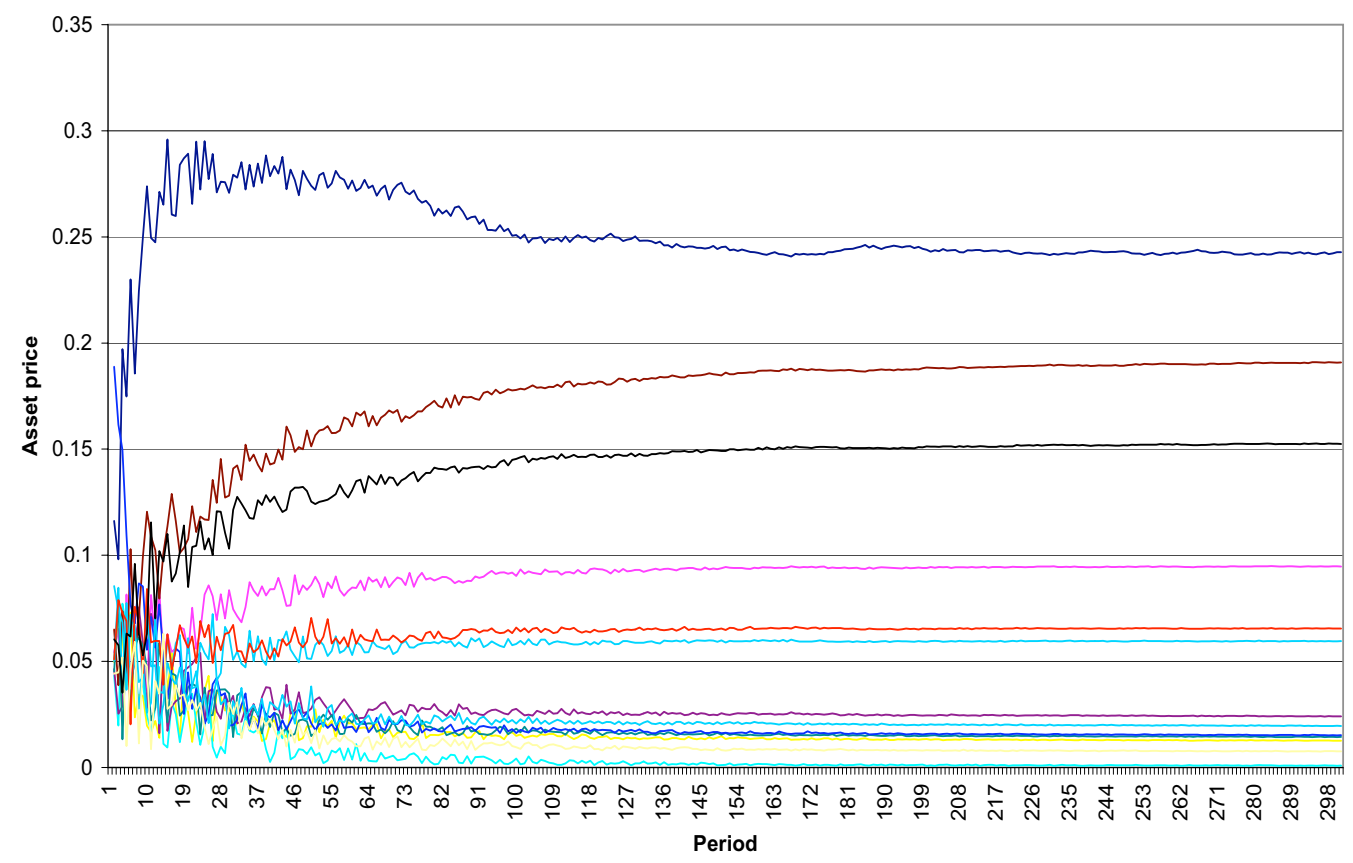

Figure 5: Evolution of share prices over time for one sample path of the dividend process in the model with noise traders.)

sets allowing the important feature of capital gains. However these authors assume a complete security market and moreover their model is based on the notion of a competitive equilibrium with portfolio rules being generated by infinite horizon expected utility maximizers. In particular then the model cannot be written as a dynamical system in which wealth evolves from one period to the next. Evstigneev, Hens, and Schenk-Hoppé (2002a) is the first dynamical systems model with long lived assets and a completely general security market. Moreover portfolio rules need not be generated by expected utility maximization. As mentioned above in that paper the local stability, the evolutionary stability of monomorphic populations is considered. Suppose that the wealth process converges to the evolutionary stable portfolio rule $\lambda^{*}$ then capital gains also converge to the dividend payoffs. Hence the strategy being best suited to the dividends will eventually also profit most from the capital gains. Note that only the evolutionary rule $\lambda^{*}$ found in Hens and Schenk-Hoppé (2001) has this property so that in the long run this strategy has the highest expected growth rate.

Let us finally compare the evolutionary portfolio rule $\lambda^{*}$ with the CAPMrule, $\lambda^{C A P M}$. According to the CAPM, a passive buy and hold strategy, one should hold a fixed fraction of the market portfolio. In the notation of this 
paper, this would translate to having the demand $a_{t, k}^{C A P M}=\gamma_{t} s_{t}^{k}$, where $\gamma_{t}=\left(\sum_{k} p_{t}^{k} s_{t}^{k}\right)^{-1}$ is some positive scalar. In terms of budget shares the CAPM-strategy is: $\lambda_{t, k}^{C A P M}=\gamma_{t} p_{t}^{k} s_{t}^{k}, k=1, \ldots K$.

The first observation is that in a rational and risk neutral market, $\lambda^{*}$ would actually coincide with the CAPM-rule because in such a market asset prices are determined by discounted expected dividends, i.e. $p^{k}=\frac{1}{r_{f}} \mathbb{E} d^{k}$, $k=1, \ldots, K$, where $r_{f}$ denotes the risk free rate of interest. As $\lambda^{*}$ gains total market wealth, prices converge to the rational and risk neutral valuation and thus $\lambda^{*}$ and the CAPM-rule will eventually coincide. Hence while $\lambda^{*}$ exploits the wealth of other strategies it will never be able to drive out the CAPM-rule. In a sense, the CAPM-rule is a imitation strategy that eventually mimics the best performing strategy.

In passing note that similar to contrarian strategies from behavioral finance the evolutionary portfolio rule eventually eliminates the market anomaly from which it lives. As long as $p^{k} \neq \frac{1}{r_{f}} \mathbb{E} d^{k}, k=1, \ldots, K$ there are excess returns and hence $\lambda^{*}$ can grow at the expense of the existing ones. And in the limit as the distribution of wealth concentrates on $\lambda^{*}$ these excess returns are removed.

\section{Conclusions}

Our simulations have shown that in competition with rebalancing rules derived from Mean-Variance-Optimization, from Maximum Growth Theory and from Behavioral Finance the Evolutionary Portfolio rule discovered in Hens and Schenk-Hoppé (2001) will eventually hold total market wealth. According to this simple rule the portfolio weights should be proportional to the expected relative dividends of the assets. This rule may be interpreted as a CAPM-rule which fixes budget shares according to the expected market capitalization and then rebalances according to these weights as prices fluctuate. For sufficiently patient investors, like pension funds or insurance companies for example, this rule promises very high proceeds. On a long horizon risk is limited - the standard deviations of the average position of the market share are very small and almost constant over time. Risk will however matter if the investor is subject to shocks that require to liquidate some of its wealth at unforeseen periods. An important and also very interesting extension of this work is to introduce such liquidity shocks in the evolutionary process of market selection. 


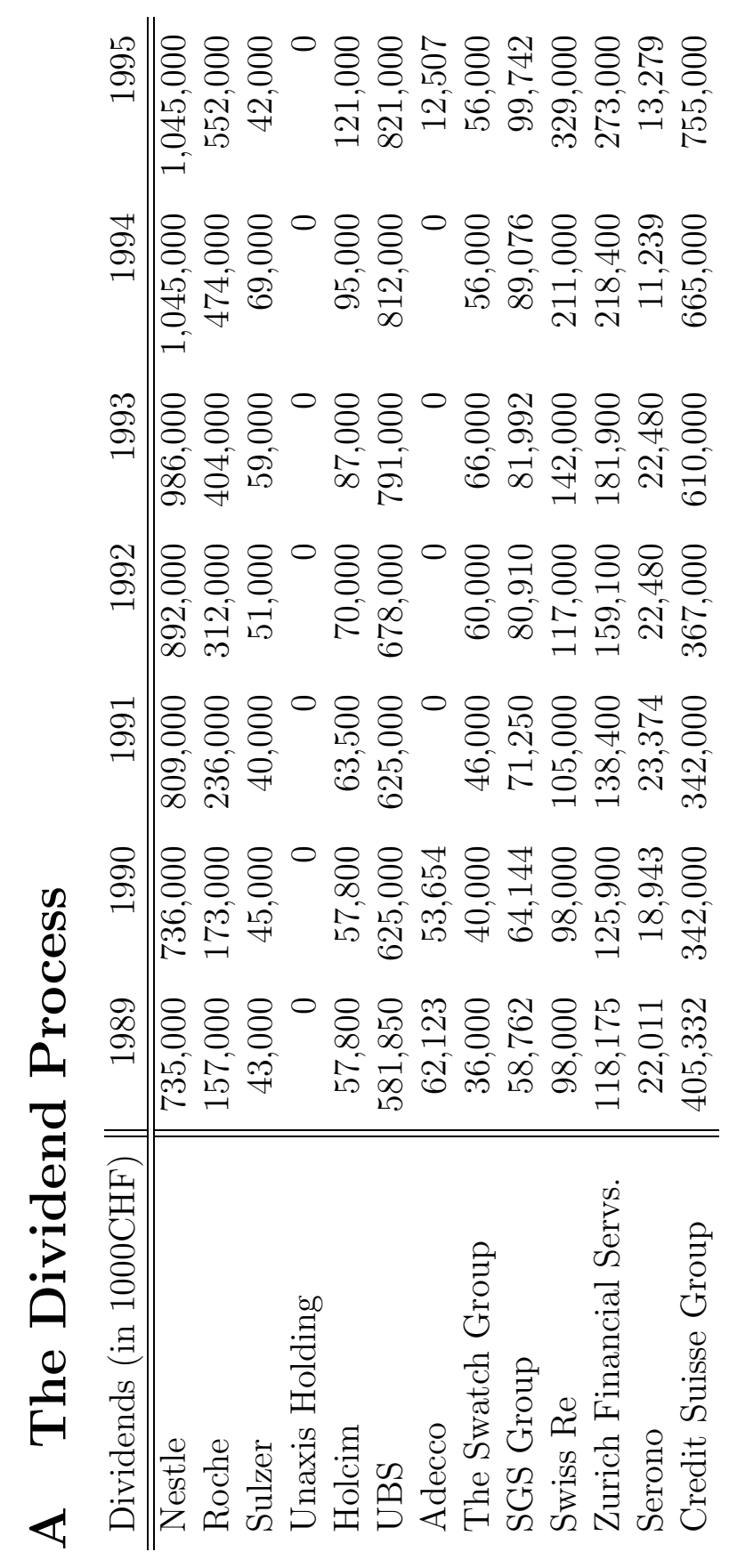




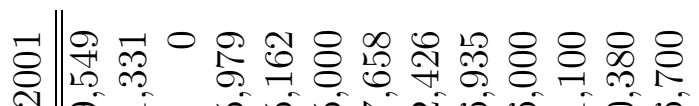

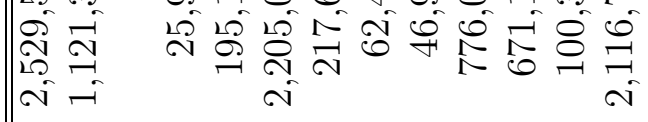

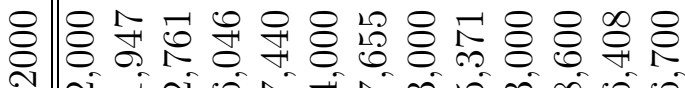

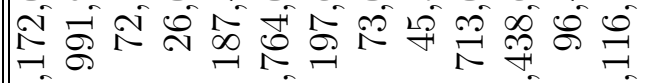

管

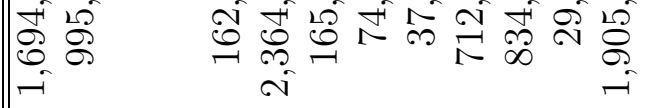

品

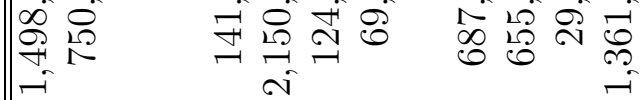

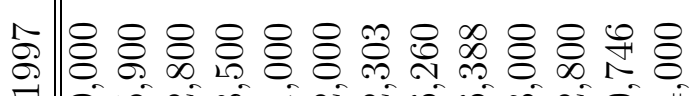

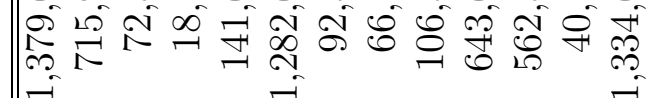

\&. \& \& \& \&

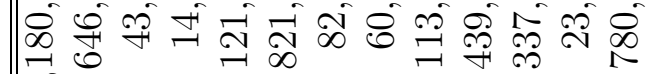

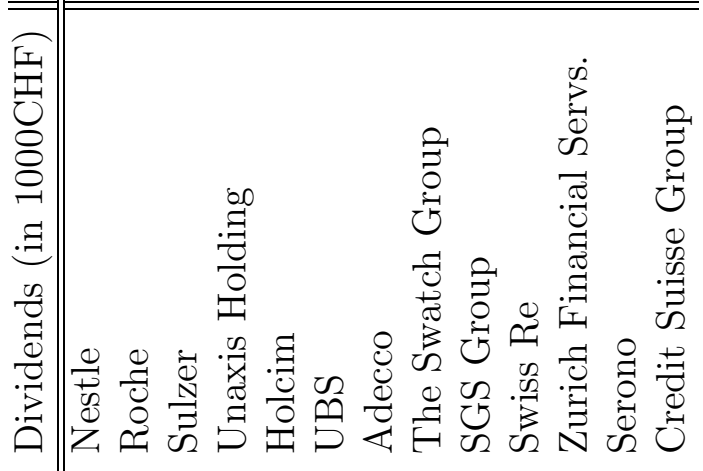




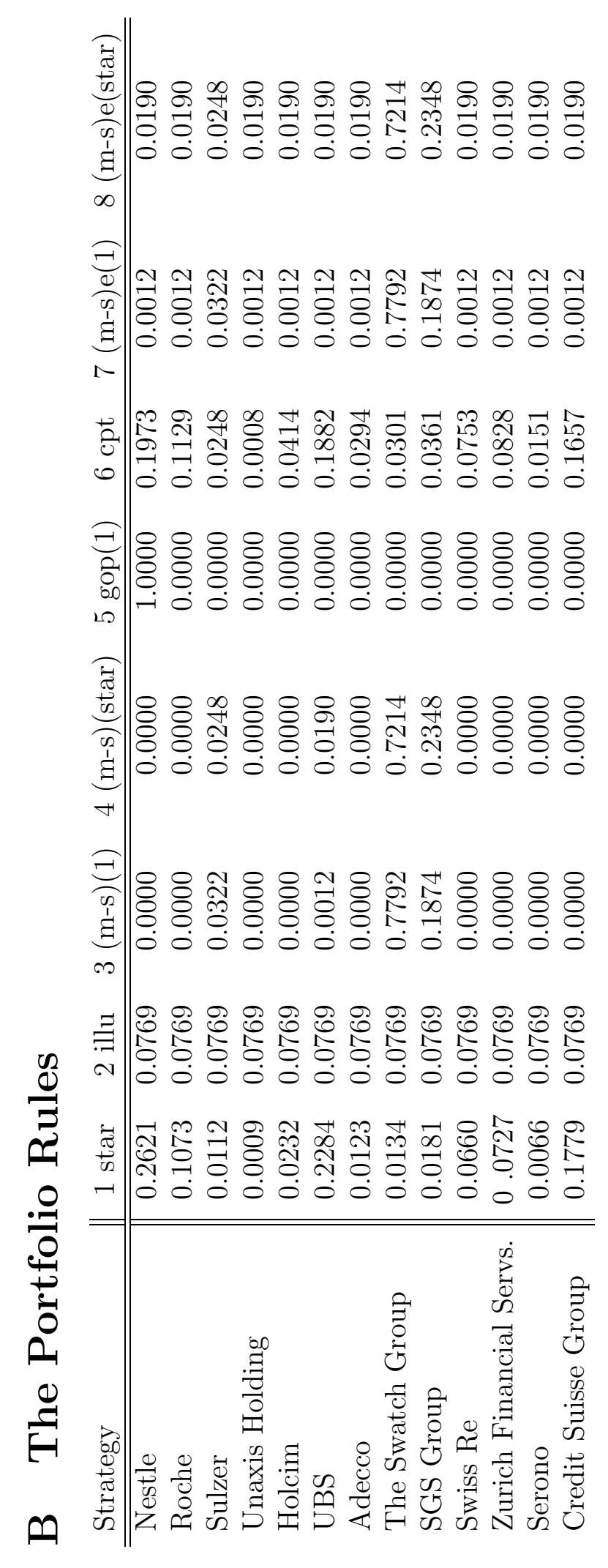




\section{References}

Amir, R., I. V. Evstigneev, T. Hens, and K. R. Schenk-Hoppé (2001): "Market Selection and Survival of Investment Strategies," Working Paper No. 91, Institute for Empirical Research in Economics, University of Zurich.

Arthur, W. B., J. H. Holland, B. LeBaron, R. G. Palmer, and P. TAYLOR (1997): "Asset Pricing under Endogenous Expectations in an Artificial Stock Market," in The Economy as an Evolving Complex System II, ed. by W. B. Arthur, S. Durlauf, and D. Lane, pp. 15-44. Addison Wesley.

Benartzi, S., And R. Thaler (1998): "Illusionary Diversification and Its Implications for the U.S. and Chilean Retirement Systems," Working Paper, University of California, Los Angeles.

Blume, L., And D. Easley (1992): "Evolution and Market Behavior," Journal of Economic Theory, 58, 9-40.

(2001): "If You Are So Smart Why Aren't You Rich? Belief Selection in Complete and Incomplete Markets," Mimeo, Cornell University.

Breiman, L. (1961): "Optimal Gambling Systems for Favorable Games," Fourth Berkeley Symposium on Mathematical Statistics and Probability, 1, $65-78$.

Brock, W. A., and C. H. Hommes (1997): "A Rational Route to Randomness," Econometrica, 65, 1059-1095.

Campbell, J. (2000): "Asset Pricing at the Millennium," Journal of Finance, $55,1515-1567$.

De Bondt, W. (1999): "A Portrait of the Individual Investor," European Economic Review, 42, 831-844.

De Bondt, W., and R. Thaler (1985): "Does the Stock Market Overreact?," Journal of Finance, 40, 793-805.

Evstigneev, I. V., T. Hens, and K. R. Schenk-Hoppé (2002a): "Evolutionary Stable Investment in Stock Markets," Working Paper, Institute for Empirical Research in Economics, University of Zurich, in preparation.

(2002b): "Market Selection of Financial Trading Strategies: Global Stability," Mathematical Finance, forthcoming. 
FAmA, E. (1965): "The Behavior of Stock Market Prices," Journal of Business, 38, 34-105.

Friedman, M. (1953): Essays in Positive Economics. University of Chicago Press, Chicago.

Hakansson, N. (1970): "Optimal Investment and Consumption Strategies Under Risk for a Class of Utility Functions," Econometrica, 38, 587-607.

Hens, T., And K. R. Schenk-Hoppé (2001): "Evolution of Portfolio Rules in Incomplete Markets," Working Paper No. 74, Institute for Empirical Research in Economics, University of Zurich.

Hirshleifer, D. (2001): "Investor Psychology and Asset Pricing," Journal of Finance, 56, 1533-97.

Kelly, J. (1956): "A New Interpretation of Information Rate," Bell System Technical Journal, 35, 917-926.

LeBaron, B., W. B. Arthur, and R. Palmer (1999): "Time Series Properties of an Artificial Stock Market," Journal of Economic Dynamics and Control, 23, 1487-1516.

Lux, T. (1994): "The Socio-economic Dynamics of Speculative Markets: Interacting Agents, Chaos, and the Fat Tails of Return Distributions," Journal of Economic Behavior and Organization, 33, 133 -165.

Markowitz, H. (1952): "Portfolio Selection," Journal of Finance, 7, 77-91.

Mas-Colell, A., M. Whinston, and J. Green (1995): Microeconomic Theory. Oxford University Press, Oxford.

Mauboussin, M. (1999): "The New Capital Market Theory," In Frontiers of Finance, Credite Suisse First Boston, London.

Rubinstein, M. (1991): "Continuously Rebalanced Investment Strategies," The Journal of Portfolio Management, Fall, 78-81.

Sandroni, A. (2000): "Do Markets Favor Agents Able to Make Accurate Predictions?," Econometrica, 68, 1303-1341.

SciubBA, E. (1999): "The Evolution of Portfolio Rules and the Capital Asset Pricing Model," Mimeo, Cambridge University. 
Shiller, R. (1981): "Do Stock Prices Move Too Much to be Justified by Subsequent Changes in Dividends?," American Economic Review, 71, 421436.

Shleifer, A. (2000): Inefficient Markets. An Introduction to Behavioral Finance. Oxford University Press, Oxford.

Tversky, A., and D. Kahnemann (1992): "Advances in Prospect Theory: Cumulative Rerpresentation of Uncertainty," Journal of Risk and Uncertainty, 5, 297-323. 